\title{
Early Requirements and Business-IT Alignment with SEAM for Business
}

\author{
Alain Wegmann ${ }^{1}$, Philippe Julia ${ }^{2}$, Gil Regev ${ }^{3}$, Olivier Perroud ${ }^{4}$, Irina Rychkova ${ }^{5}$ \\ $1,3,5$ Ecole Polytechnique Fédérale de Lausanne (EPFL), School of Communication and \\ Computer Science, CH-1015 Lausanne, Switzerland \\ ${ }^{2}$ Cambridge Technology Partners, $\mathrm{CH}$ - 1214 Geneva, Switzerland \\ ${ }^{4} @ G e K o, C H-1071$ Chexbres, Switzerland \\ \{1alain.wegmann@epfl.ch, ${ }^{2}$ philippe.julia@ctp.com, ${ }^{3}$ gil.regev@epfl.ch, \\ olivier.perroud@ageko.ch, ${ }^{5}$ irina.rychkova@epfl.ch\}
}

\begin{abstract}
The early requirements of an IT system should be aligned with the organization's business imperatives. To understand these imperatives it is necessary to understand the organization's position within its environment. SEAM for Business is a method designed for analyzing the competitive environment of an organization, including its relationships with its customers, partners, and market regulators. From this analysis, the main requirements of the IT systems can be inferred. We illustrate the use of SEAM for Business with a real project aimed at redesigning the website of a consulting company.
\end{abstract}

\section{Introduction}

Our purpose in this paper is to illustrate how a competitive environment analysis can affect the early requirements for an IT system. For this, we describe SEAM for Business and illustrate with a concrete example how such a method can influence the early requirements of an IT system. We chose a project of website redesign as an example.

The website we consider belongs to Cambridge Technology Partners (CTP). CTP develops IT solutions and is active in five segments: e-government, financial services, consumer goods, pharmaceuticals, and telecommunication. SEAM for Business was applied to understand the competitive environment of CTP and to infer from them the early requirements for the website. The models presented in this paper illustrate the competitive analysis realized at CTP. So, the example is real but is , as yet, unimplemented.

SEAM (Systemic Enterprise Architecture Methods) designates a set of systemic methods that addresses business, enterprise architecture [10] and software [9]. All methods [8] are based on General Systems Thinking [11]: the perceived reality is represented as hierachical systems. Each system can be analyzed as whole or as composite. For example, in SEAM for Business, a market segment is considered as a system. It can be modeled as a whole, showing its externally visible properties (e.g. segment size in units sold or dollars), or as made of interrelated parts (e.g. value networks and their relationships).

\section{World, Segment and Value Network}

In SEAM for Business, the most abstract system analyzed is the world. It enumerates all segments relevant for a company and is useful to reason about inter-segment dynamics (e.g. gray market).

A market segment is a large identifiable and homogeneous group of customers [4]. In SEAM for Business, we broaden this definition of segment to include all the players related to a particular business venture: e.g. the company that supplies the product or service, its partners, its competitors and their partners, and the market regulators.

Within a segment, we analyze four main aspects: (1) How companies cooperate together to achieve commercial objectives - we call these group of companies value networks; (2) How the features provided by supplier value networks bring value to adopter value networks - we call this the supplier / adopter relationship; (3) How companies can influence each other - we call these influences linkages; and (4) How the relations between the players are maintained stable, in part by regulators. Figure 1 illustrates the e-government segment for CTP. 


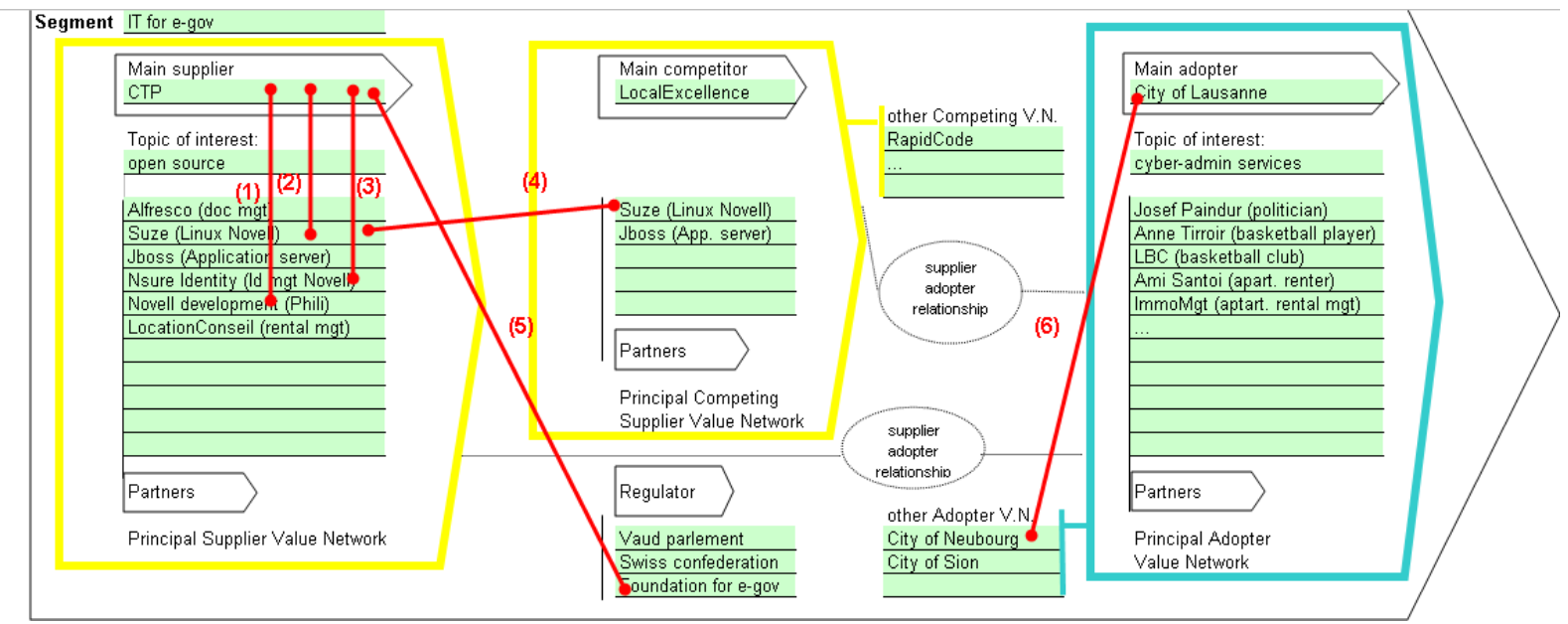

Figure 1: The e-government segment

A value network (VN) [7] is a system, i.e. a set of interrelated companies that share a common topic of interest. One company, the main one, is considered as central in the analysis; the others are partners. The contribution of each company is represented by its role (given in parenthesis after the company name). We recommend naming explicitly the actors (e.g. companies, individuals) in the value network and not using generic descriptions. This makes the model significantly more concrete. This is similar to the concept of digital persona [1].

We represent all value networks that supply the egovernment service: the principal supplier value network (CTP Value Network), the principal competitor supplier value network (LocalExcellence Value Network) and the other competing supplier value networks (RapidCode). Within the CTP value network, CTP's partners are represented.

We also represent the value networks that benefit from the e-government service. These are the adopter value networks. One of them is considered as the principal adopter value network (in our example, the City of Lausanne), the others - the other adopter value networks - are only listed for reference (in our example, two other Swiss cities, Neubourg and Sion the ones in which to do a repeated sale once the City of Lausanne has adopted CTP as supplier). Within the City of Lausanne value network, its partners are represented. They are all interested in cyberadministration and in its concrete services. In particular, Anne Tirroir plays basketball in the Lausanne Basket Club that rents a sports hall from the City. Another service is apartment renting to lowincome people. Ami Santoi and ImmoMgt are interested in that service. A third aspect is illustrated by Josef Paindur who is a politician and is interested in the development of the cyber-administration. This group of people represents entities that would benefit from the services developed by CTP for the City of Lausanne.

Finally, we represent the regulators that control the segment; in our case: the state, an organization that promotes the use of open software in public administrations and the Swiss Confederation.

The numbered lines in Figure 1 represent linkages. A linkage is a special relation between two companies that might be leveraged or that might bring a risk. The linkages 1, 2 and 3 represent the fact that, as CTP is owned by Novell, the company has a special relationship to Suze, Nsure and to the Novell development goup that developed an application in Philadelphia. The linkage 4 represents a potential conflict of interest; the linkage 5 the possibility to be active in the organism promoting e-government; and the linkage 6 a relation between customers. Identifying linkage is useful to define marketing strategies and to gain a competitive advantage.

\section{Supplier / Adopter Relationship}

The Supplier / Adopter Relationship (SAR) describes the relationship between a supplier value network and an adopter value network. The SAR is represented as an ellipse in the segment (Figure 1). The SAR can be described in detail with the SAR form, Figure 2. The SAR represents the adoption process (illustrated by the large arrows in Figure 2). This process has the following elements: 


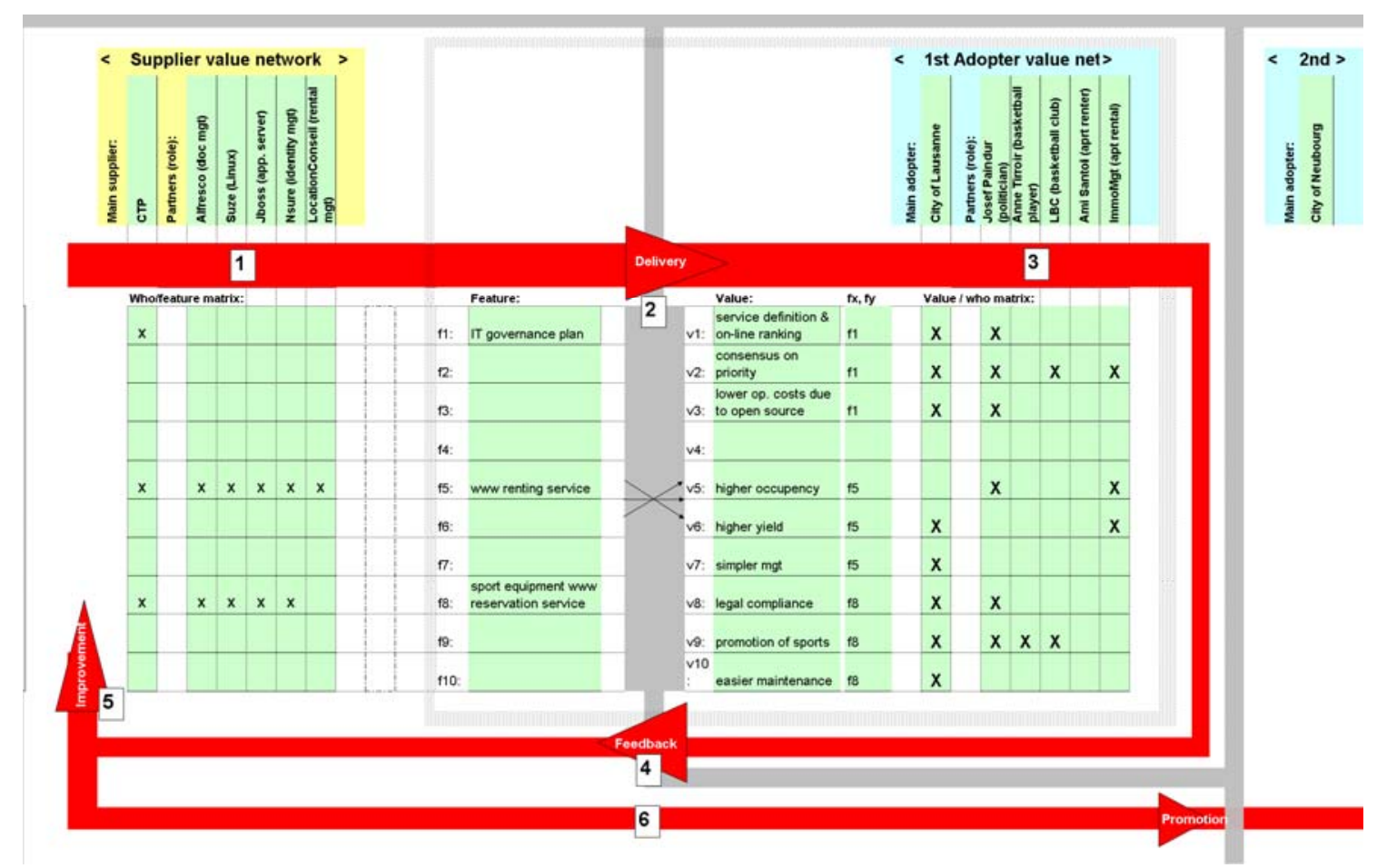

Figure 2: Supplier Adopter Relationship (SAR) in the e-gov segment

(1) who in the supplier value network provides which feature, (2) which set of values correspond to which set of features, (3) who in the adopter side benefits from which of these values (4) how these values are measured, (5) how these measures drive improvements, (6) how marketing material is developed from this experience to acquire new customers.

In our example, three main features and the corresponding values are represented. First, the feature f1 (IT governance plan) maps to the values v1, v2 and v3. Value $v 1$ is the inventory of all services that can be provided in e-government. The main beneficiaries are the City of Lausanne and Josef Paindur, the elected official who is interested in showing that the City manages tax payer money in the most appropriate form. Value v2 is the consensus on the ranking among all the city partners, a consequence of the method adopted by CTP to make the IT governance plan. The value v3 explains why the City of Lausanne chooses open source tools. CTP needs to show that its mastering of these tools helps the City of Lausanne to be more efficient while providing better services.

Feature f5 and values v5 to v7 provide a summary of the $1^{\text {st }}$ service that is implemented: the management of the apartment for rent.

Feature f8 and values v8 to v10 provide an overview of the second service, the rental of sports equipment. As the SEAM model is developed to understand how to structure CTP's website, the services are not described in further detail. If the project goal had been the development of the services, a specific SEAM analysis could have been made for each of them.

The left part of the SAR form (Figure 2) describes the responsibility matrix between the companies in the principal supplier value network and delivered features. For example, CTP's IT governance plan is developed without any help from CTP's value network. Apartment and sports equipment rental services are developed in collaboration with all technical partners. The apartment rental management service is developed in collaboration with a partner.

The right part of the SAR form is the matrix that maps the features offered by the supplier company to values for the beneficiary companies or people. For example, the consensus on the ranking of the cyberadministration services is a value for all partners of the City of Lausanne. For the apartment rental service, the high occupancy that the system will enable and the higher yield are benefits for the company that provides the apartments for rent. This is a key feature; otherwise it would be difficult for the City of Lausanne to obtain apartments for low-income people. The analysis also highlights that Josef Paindur is interested in the availability of apartments and in the legal compliance 
of the management of the sports equipment (by law, the local sports clubs should be able to access the equipments owned by the city).

In summary, the SAR analysis is essential to concretely understand the value creation process. With this analysis, it is possible to understand the differing viewpoints of the adopters and the suppliers. The SAR is also useful to understand what information needs to flow between the supplier and the adopter value networks (and vice-versa).

\section{IT System Requirement}

To define the early requirement for a company's website, we consider the model of the world, of the segments and of the supplier/adopter relationships and we define how they relate to the future website. In the example of CTP, the world model defines five segments. Recall that a segment groups members (customers, competitors, regulators) that have similar properties. Therefore, the goal is to have a specific message for the members of each segment, the website needs to have a specific section for each segment. The information presented in each section of the website is derived directly from the segment and from the SAR analysis. The requirements can be deemed to be correct if, for example, when Josef Paindur (the elected official) visits the CTP website, he can gather information that is directly useful for promoting open solutions to his colleagues in other cities. Ideally, the City of Lausanne should also be able to refer to the CTP website to explain the benefits of the open source strategy. To clearly show the value to a potential adopter, the information needs to be very specific. The SEAM for Business models help here because they contain specific examples of people and their needs e.g., Anne Tirroir, the basketball player.

\section{Related Work}

SEAM for Business is a Market-Driven Requirements Engineering (MDRE) method [6]. These methods have in common their focus on products that are developed for many customers instead of just one. MDRE methods incorporate vocabulary and techniques from marketing methods (e.g. EBMF [5] provides a method based on Balance Scorecards [3].). The MDRE method that is the closest to SEAM is e3value [2]. e3-value provides a tool to analyze value and monetary exchanges between companies active in a segment. The key feature of e3-value is the quantitative analysis. In SEAM we are mainly qualitative. SEAM analysis of the segment is more structured (i.e. adopter value network, competing value networks) as e3value analyze the companies' interactions as a flat network. SEAM uses the same technique for modeling the organization of a company and the construction of the IT system (not possible in e3value).

\section{Conclusions}

An important trend in IT system development is business / IT alignment. To develop an IT system aligned with the business, it is important to understand the business requirements. In this paper, we show that - in the early requirement phase - performing a competitive environment analysis can lead to the identification the business requirements for the IT system. We also present SEAM for Business, a systemic method designed for the qualitative analysis of the competitive environment.

\section{References}

[1] Cooper, A., The Inmates Are Running the Asylum: Why High Tech Products Drive Us Crazy and How To Restore The Sanity, Sams Publisher, 1999

[2] Gordijn, J. and Akkermans, J.M., "Value-based requirements engineering: exploring innovative e-commerce ideas”, Requirement Engineering Journal, p. 114 - 134, July 2003

[3] Kaplan, R. and Norton, D., The Balanced Scorecard: : Translating Strategy into Action, Harvard Business School Press, 1996

[4] Kotler, P., Marketing Management, The Millenium Edition, Prentice Hall, 2000

[5] Osterwalder, A. and Pigneur, Y., "An e-Business Model Ontology for Modeling e-Business", 15th Bled Electronic Commerce Conference, Bled, 2002

[6] Regnell, B. and Brinkkemper, S., "Market-Driven Requirements Engineering for Software Products," in Engineering and Managing Software Requirements, Aurum, A. and Wohlin, C., eds., Berlin: Springer, 2005, pp. 287-308. [7] Stabell, C. B. and Fjeldstad, Ø. D., "Configuring value for competitive advantage: on chains, shops, and network", Strategic Management Journal 19(5): p. 413 - 437, 1998

[8] Wegmann, A., "On the Systemic Enterprise Architecture Methodology (SEAM)”, International Conference on Enterprise Information Systems (ICEIS), Angers, France, 2003

[9] Wegmann, A, Balabko, P., Lê, L.S., Regev, G. and Rychkova, I., "A Method and Tool for Business-IT Alignment in Enterprise Architecture”, CAiSE`05 Forum , 2005

[10] Wegmann A., Regev, G. and Loison B., "Business and IT Alignment with SEAM", 1st International Workshop on Requirements Engineering for Business Need, and IT Alignment (REBNITA2005), 2005

[11] Weinberg, G.M., An Introduction to General System Thinking, Wiley \& Sons. New York, 1975 